\title{
CORRECTION ARTICLE
}

$\underline{\text { ID of article to be corrected (previous erroneous form): }}$

Mohammed Salam Taha Taha, Ali Ateş, Aziz Hakan Altun, Eyüb Canl1, 2018, Natural convection from perforated vertical fins with different hole diameters, International Journal of Energy Applications and Technologies 5(4) [2018] 174180, doi: $10.31593 /$ ijeat.505116

ID of corrected article (true and current form):

Mohammed Salam Taha Taha, Ali Ateş, Aziz Hakan Altun, Eyüb Canl1, 2020, Natural convection from perforated vertical fins with different hole diameters, International Journal of Energy Applications and Technologies 7(4) [2020] 154160, doi: 10.31593/ijeat.505116

Brief correction explanation: On demand of the authors, Figure 8 and Figure 9 of previous version are replaced according to corrections due to honest error in data reduction. Evaluation and comments are corrected accordingly.

Editorial note: This document contains corrected article and author correction notes respectively.

Ilker ORS

Editor in Chief

International Journal of Energy Applications and Technologies 


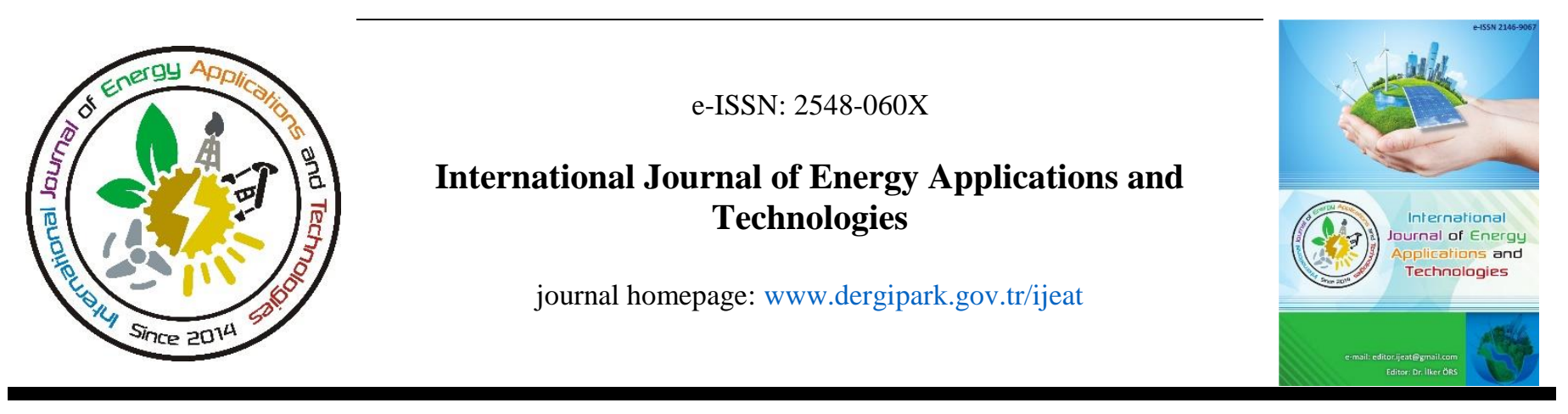

Original Research Article

\title{
Natural convection from perforated vertical fins with different hole diameters
}

\author{
Mohammed Salam Taha Taha ${ }^{1}$, Ali Ateş ${ }^{2}$, Aziz Hakan Altun ${ }^{3}$, Eyüb Canl1 ${ }^{4 *}$ \\ ${ }^{1}$ Mechanical Engineering, Natural and Applied Sciences Institude, Konya Technical University, Konya, Turkey \\ ${ }^{2}$ Machine and Metal Technologies Department, Selcuk University, Konya, Turkey \\ ${ }^{3}$ Department of Airframe and Powerplant Maintenance, Selcuk University, Konya, Turkey \\ ${ }^{4}$ Mechanical Engineering Department, Selcuk University, Technology Faculty, Konya, Turkey
}

(Corrected Version: Figure 8 and Figure 9 of earlier version are replaced according to corrections due to honest error in data reduction. Evaluation and comments are corrected accordingly. Previous version doi: 10.31593/ijeat.505116)

ARTICLE INFO
* Corresponding author
ecanli@ selcuk.edu.tr
Received December 28, 2018
Accepted December 31, 2018
Published by Editorial Board
Members of IJEAT
C This article is distributed by
Turk Journal Park System under
the CC 4.0 terms and conditions.
doi: $10.31593 /$ ijeat.505116

\begin{abstract}
Natural convection is a physical mechanism that is mostly benefited in cooling of electronics. Due to the variety of the geometrical and operational parameters, industrial and scientific studies are continuing for better performance. One of the focuses is on perforations of heat sink fins as a passive flow control technique. This work experimentally investigates a sinusoidal wavy fin heat sink after fins were perforated with two different hole diameters. Heat sink was heated by using an electrical resistance for six different heating powers. The temperature at the heater-heat sink interface was measured with the aid of four thermocouples. Transient and steady temperature values were measured and then recorded by means of a data-logger. The details of the experimental setup are given alongside of visuals. It is desired to state some assessment and evaluations about the experimental setup. Related literature studies are also summarized in the introduction section. Heat transfer, Rayleigh and Nusselt numbers were calculated and compared with each other and parameters by means of $2 \mathrm{D}$ plot graphics. The time for reaching steady state is changing between 1.5 to 2 hours. Average wall temperature changes linearly with heating power. Average wall temperature values are between 300 and 370 Kelvin. Nusselt number increases with increasing Rayleigh number as expected. While Rayleigh number changes between 500,000 to 5,000,000 Nusselt number approximately increases from 18 to $25.3 \mathrm{~mm}$ perforations yield better results in terms of Nusselt numbers, which means better thermal convection. Surface temperature trends are similar according to power increments. Considering experimental uncertainty, general performances of the two heat sinks are found similar. Some remarks for the future work are given in conclusion section.
\end{abstract}

\section{Introduction}

The methods that are being used for cooling electronic devices vary greatly depending on the applications and required cooling capacity. The fins are widely used in the cooling of computer processors, aircraft engines, air-cooled automobile engines, generators, motors, transformers, refrigerators and other electronic devices. It is a very important element in the geometry of heat sinks. Many studies have been conducted to determine the performance of heat transfer surfaces. These studies can be exemplified as; different geometry designs, the arrangement of fins, different position angles, holes on the fins, hole geometries. One of the methods of improving the natural convection heat transfer using the heat sinks is to drill holes. Because boundary layer formed on the fins is broken by the opening holes and 
possibility of better heat transfer is achieved. Before giving detailed information about the study, review of the related literature is given below.

Harahap and McManus [1] worked on rectangular fins on a horizontal plane. Heat sinks consist of eight different lengths and ranges of rectangular shaped fins. In their work, the flow area is examined. They have seen that air flows through the open ends goes up from the middle of the fin for the long fins. They stated that the fin length is the most important geometric parameter. Liang and Yang [2] investigated the effects of friction loss performance and perforation geometry on heat transfer of compact heat exchangers with perforated rectangular plate surfaces. Patankar et al. [3] report that perforated blades can be used for effective heat transfer area and/or heat transfer coefficient. According to the authors, the change in the size of the surface area depends on the geometry of the holes. In 2008, Jasim et al. [4] tested the natural convection of a perforated fin. The temperature distribution was examined for a series of rectangular fins (15 fins). Cross-sectional area $(100 \times 270 \mathrm{~mm})$ placed on different vertical bodies. Molds of the holes comprise 18 circular holes. Experiments were carried out in a pilot facility. They showed that the heat transfer rate and the heat transfer coefficient increase when the diameters of the holes are increased. Shaeri et al. [5] investigated turbulent fluid flow and convection heat transfer around a different number of perforations and a series of rectangular solids of different sizes. Results are based on the fin thickness from 2000 to 5000 and $\operatorname{Pr}=0.71$. The aim of their study was to investigatethe mechanism of heat transfer by changing surface geometryand heat exchanger configuration. They stated that increasingthe number of holes, the temperature at the base of the finsand the tip of the fin becomes greater, which means that theefficiency of heat transfer between the surface and the flowof fluids with convection is higher.

Masao et al. [6] report awork in which the surface has many perforations and is bentto form a trapezoidal shape. Dimensionless correlations onheat transfer and pressure drop are presented. Kumbhar et al.

[7] tested different shape of holes that give different effects to heat transfer coefficient, low pressure and heat distribution. The heat transfer rate is different for different materials. Their experiment was carried out with triangular shape of the hole at the tip of the fin. Similar result was found with triangular and elliptic perforations in the paper of Qui et al. [8]. The heat transfer coefficient increases, the pressure drop decreases and the temperature distribution throughout the fins increases. Al-Essa and Al-Odat [9] examined the effect of triangular perforations on the heat transfer performance of a plate fin exposed to natural convection. They confirmed that they had optimum drilling size and optimum gap values. It is claimed that it can give the maximum heat dissipation rate through the perforated fin.
Kim [10] compared the thermal performance of pin fin heat sink and plate fin heat sink for various channel lengths and blade heights.

This work distinguishes from the literature by its specific sinusoidal wavy fins with a certain amplitude on a base plate as a heat sink for natural convection heat transfer. Fin amplitude is arranged as fin height divided by $30(\mathrm{H} / 30)$. Also $3 \mathrm{~mm}$ and $6 \mathrm{~mm}$ inline symmetrical holes were drilled on two identical heat sinks in order to show their effect on the heat transfer. An experimental setup and a procedure were utilized which are also explained in the following sections. This experimental data is contributing the literature as a validation tool for Computational Fluid Dynamics (CFD) and possible empirical correlations. The data can also be used directly for industrial purposes since the operational conditions are very similar to cooling of electronics.

\section{Material and Methods}

This section contains two subsections. The first one gives information about the heat sinks that are investigated in respect of the natural convection heat transfer and the experimental equipment that were used for the investigation. The second subsection presents the equations that are used for data reduction.

\subsection{Fins and equipment}

Technical drawings of the heat sinks are given in Figure 1 and 2 , respectively for $3 \mathrm{~mm}$ and $6 \mathrm{~mm}$ hole dimensions.

These two heat sinks were placed on a heater in an insulated box in order to ensure one dimensional conduction towards heat sinks. Heat sinks that are located on the heater and insulation box are given in Figure 3. Complete test setup is given in Figure 4. The power of the electrical heater is arranged by a dimmer. The power of the electrical heater is read from wattmeter screen. Yet, it is also verified by calculating the power using the values of electrical current and voltage measured by a digital multimeter (VOM). Temperatures were recorded by a 10 channel data-logger. Only five thermocouples were used during experiments. One of them was for ambient temperature and remaining four were for the wall temperature of the heat sink. Four thermocouples for the wall temperature were embedded in the surface of the heat sink that was contacting to the heater. Their average was used during the calculations.

Figure 5 is given as an example of the thermocouple measurements by means of the data-logger. The image is from the interface of the data-logger. As seen in the figure, temperature resolution is 0.1 Kelvin or Degrees Celsius. Experiments were conducted for time periods between 4000 to 8000 seconds. Steady state operation conditions were achieved for these time periods. Steady state temperature values were used in calculations.

The experimental setup is an improved version of a previous work [11]. 


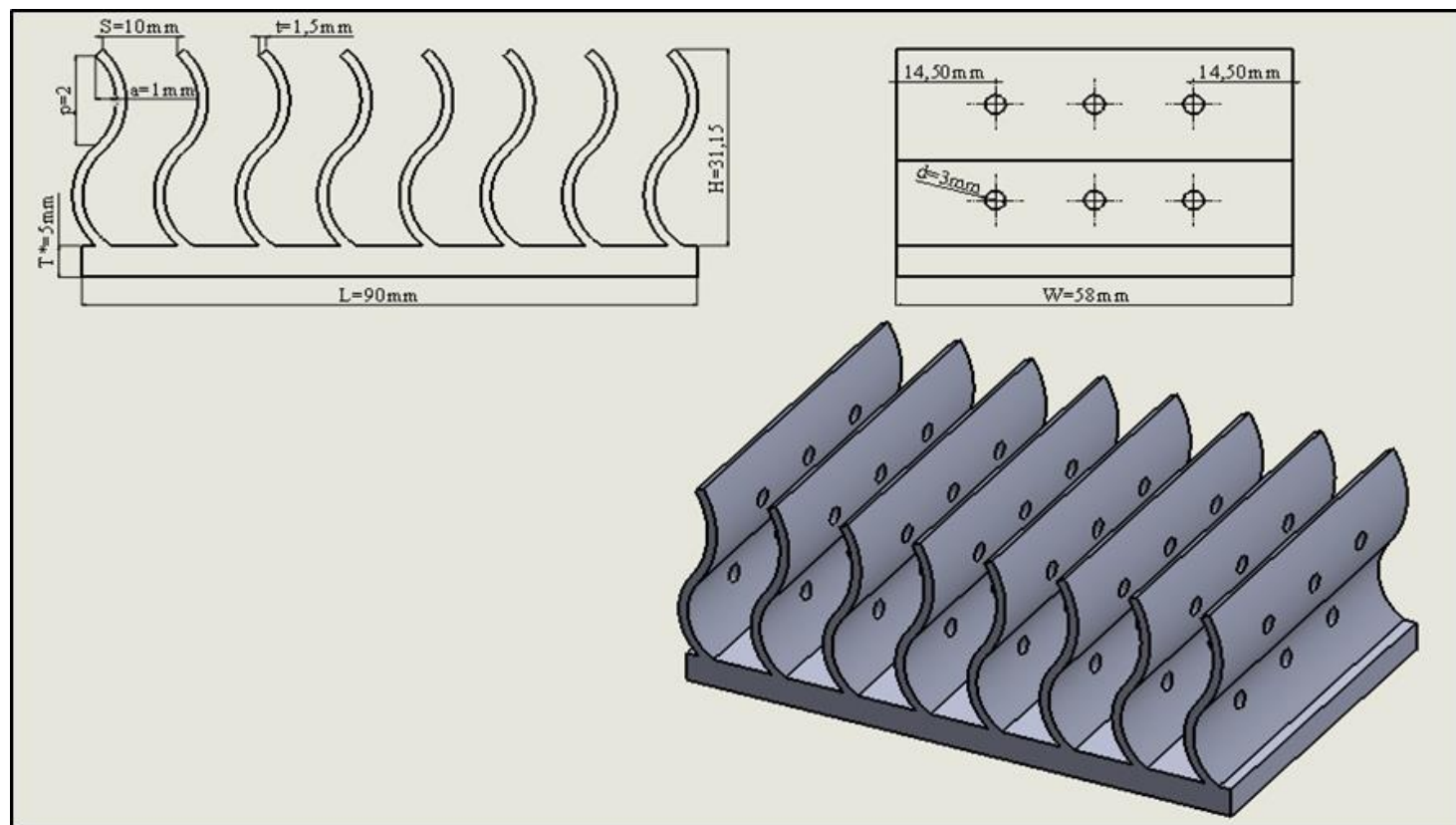

Figure 1. Sinusoidal wavy fin heat sink with $3 \mathrm{~mm}$ holes

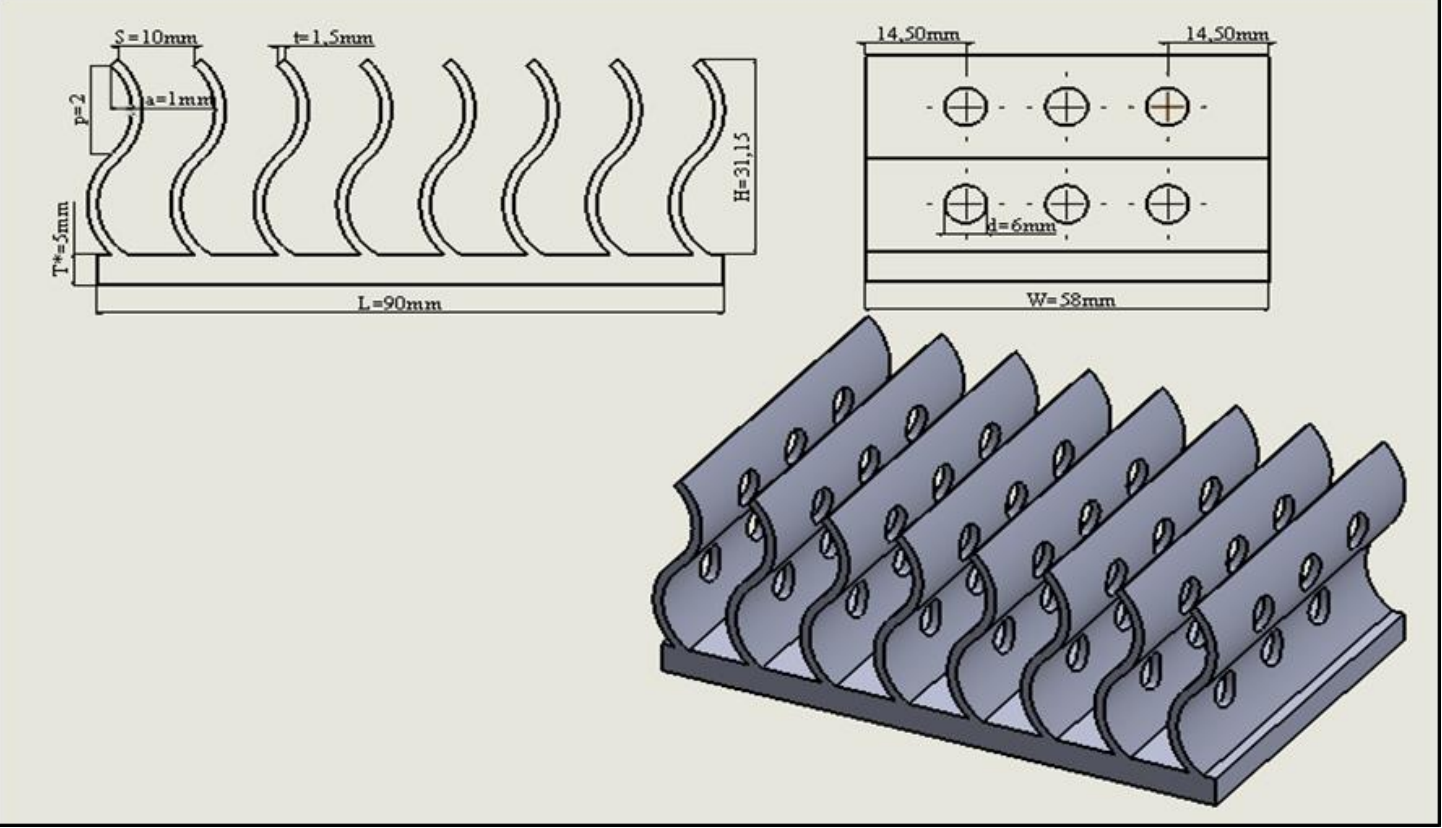

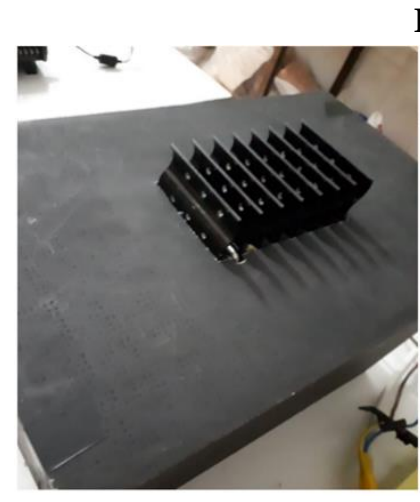

a- $3 \mathrm{~mm}$ perforations

Figure 2. Sinusoidal wavy fin heat sink with $6 \mathrm{~mm}$ holes

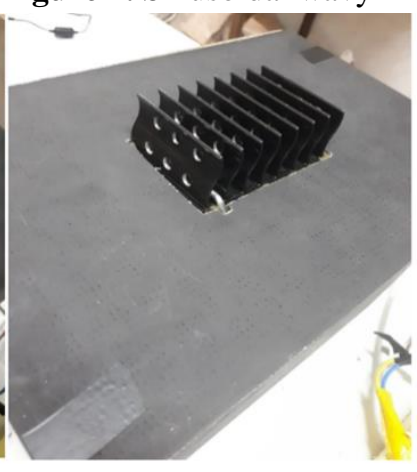

b- $6 \mathrm{~mm}$ perforations

Figure 3. Heat sinks on experimental stand

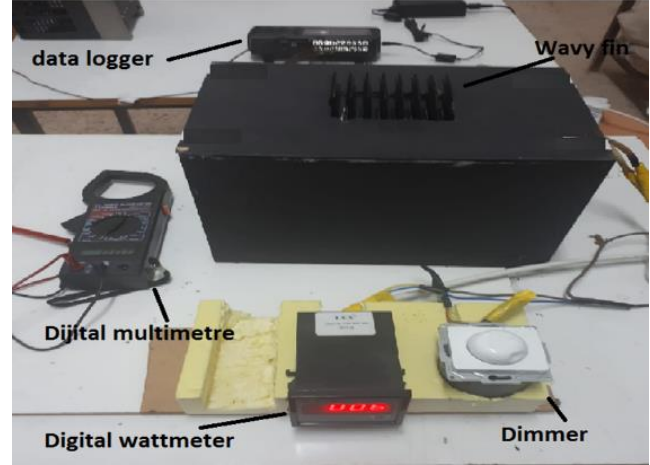

Figure 4. Experimental setup 


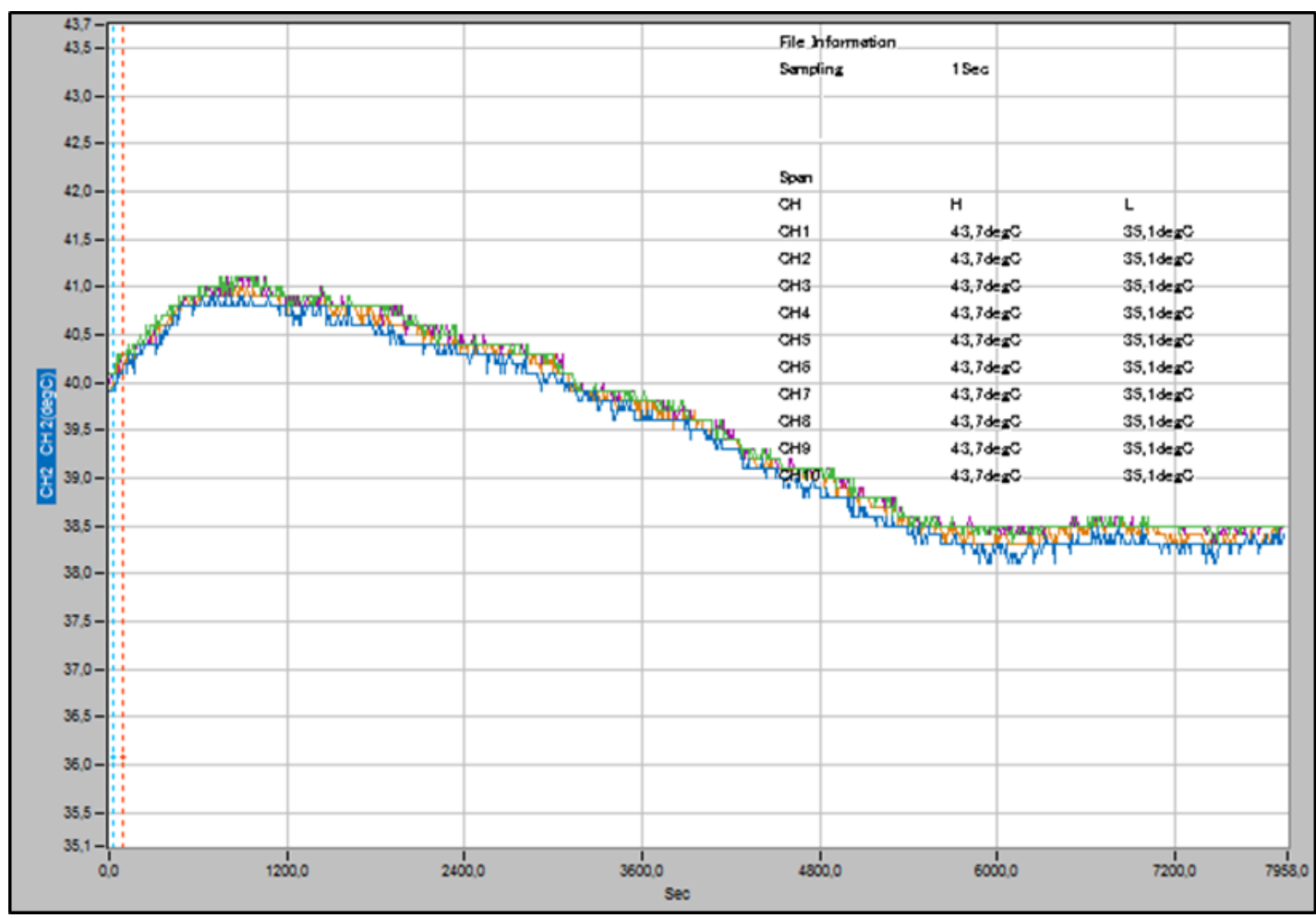

Figure 5. Interface of data-logger showing the measurements of the thermocouples

\subsection{Data reduction}

Data reduction equations and flow are also the same of a previously conducted MSc work and a report about it can be found in a journal paper [11].

For the steady state condition, total heat input to the system is equal to heat transfer from the system. This applies to the all test sets. The following formulas are used for data reduction. Heat sink material is assumed isotropic and has constant thermal conduction.

All symbols and abbreviations are explained in the Nomenclature section. Rayleigh number is given in equation (1). Volumetric expansion coefficient is given in equation (2).

$$
\begin{aligned}
& R_{a}=\frac{g \cdot \beta \cdot \Delta T \cdot L^{3}}{\alpha \cdot v} \\
& \beta=\frac{1}{T_{f}}
\end{aligned}
$$

For determining the film temperature in the volumetric expansion coefficient, (3) is given as the following. In a similar way, temperature difference for the heat transfer is given in (4).

$$
\begin{gathered}
T_{f}=\frac{T_{w}+T_{\infty}}{2} \\
\Delta T=T_{w}-T_{\infty}
\end{gathered}
$$

Nusselt number and coefficient of convection in this number is given in equations (5) and (6) respectively.

$$
\begin{aligned}
& N_{u}=\frac{h \cdot L}{k} \\
& h=\frac{Q}{A \cdot \Delta T}
\end{aligned}
$$

The surface areas in the existence of the holes are calculated by equation (7).

$$
A=W . H-n \cdot \pi \cdot r
$$

Electrical power is equal to the heating power and it is given in equation (8).

$$
Q=P=V . I
$$

\section{Results and Discussion}

The first two figures in this section are given for the transition from transient to steady state of experiments in Figure 6 and 7 , respectively for $3 \mathrm{~mm}$ hole diameter and $6 \mathrm{~mm}$ hole diameter. Both figures show that experiments continued sufficiently long to observe the temperature change of the heat sink versus time. Looking to the final parts of the trends, approximately $5 \mathrm{~W}$ heating power increase leads to about 10 $\mathrm{K}$ increase in averaged wall temperature. Some instant changes are visible in some of the trends. These are due to the rearrangement of the heating power since the changing temperature of the heater also changes its resistance value and hence the heating power changes. For those instances, heating power was rearranged. The rearrangement does not increase the time to reach steady state too much, because the temperature difference between heat sink and ambient is already close to its final value. Nevertheless, recording 
heating power would lead to better flexibility in calculations and instantaneous heat transfer values. Also, a control device or system would be good for controlling the power of the heat source since the resistance of the heater changes as the heat sink temperature increases. Another fact about final temperatures of the heat sink according to the heating power is the ambient temperature. When ambient temperature is relatively high, heat sink final temperature becomes high in order to maintain the heat transfer rate of the heat source. Final temperatures for heating powers are given in Figure 8.

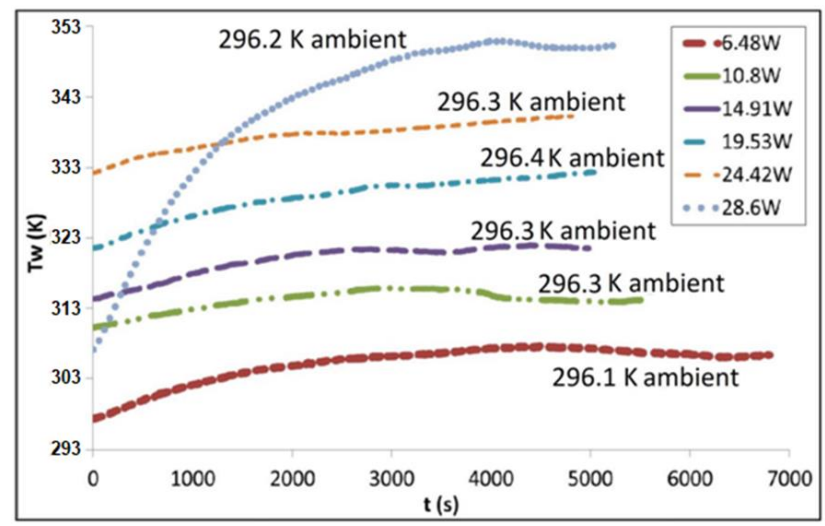

Figure 6. Changes of fin temperature versus time for $3 \mathrm{~mm}$ case

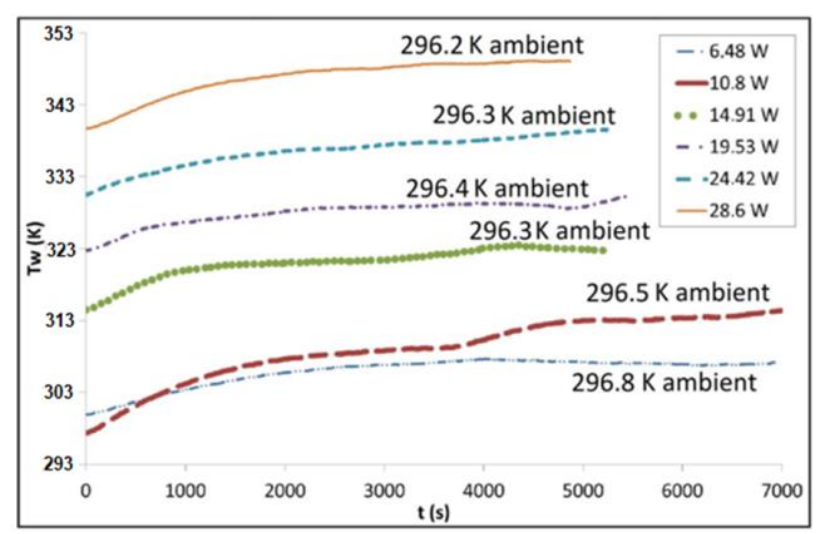

Figure 7. Changes of fin temperature versus time for $6 \mathrm{~mm}$ case

Six heating power values are seen for each heat sink when Figure 8 is examined. Although absolute power values are not coinciding, the important outcome is the slope of the trends. A lower slope means less surface temperature increase with power increments. Examination of the slopes exhibits a similar behavior in terms of surface temperature. Therefore, for industrial applications, investigated heat sinks do not differ from each other significantly. Higher temperatures for $3 \mathrm{~mm}$ heat sink are due to differences of ambient air temperature. In order to justify this statement and make a clear comparison in terms of heat transfer, dimensionless comparison is needed. Hence, Figure 9 is provided showing Nusselt numbers of the heat sinks versus Rayleigh number. Of course, ambient temperature values are also used in calculation of Nusselt numbers. Thus, Figure 9 is the final comparison for evaluating heat sinks comparatively.

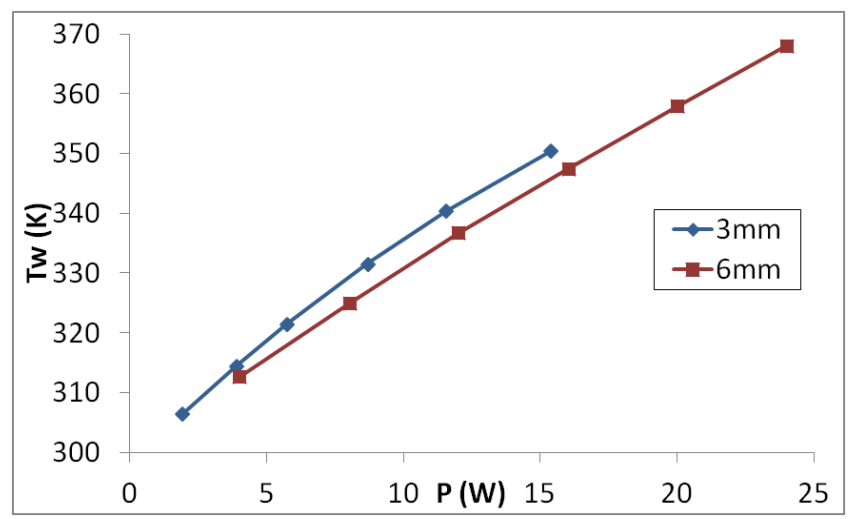

Figure 8. Average fin temperatures for tested heating powers and hole diameters

Figure 9 obviously shows that $3 \mathrm{~mm}$ hole diameters on the same fin shape exhibits significantly better convection heat transfer. Since almost all parameters for the heat sinks are same except the hole diameters, it can be concluded that 3 $\mathrm{mm}$ holes lead to better flow mixing and convection in combination with the form of the fins. It should also be mentioned that Nusselt number is drawn depending on Rayleigh number. Rayleigh number is an indicator of natural convection flow. As fluid surrounding the fins gets higher temperatures due to thermal convection, fluid expands and its density becomes lower. Due to Buoyancy forces, a fluid motion occurs. Form of the fins, combining with the existence of the perforations, alter this fluid motion and leads to different thermal convection rates. As $3 \mathrm{~mm}$ hole diameter resulted better convection heat transfer, and considering that heat transfer area is also higher for $3 \mathrm{~mm}$ case, this result indicates that there is an optimum between non perforated fins and $6 \mathrm{~mm}$ perforation. The optimum should be around 3 $\mathrm{mm}$ diameter since it gives better results comparing to $6 \mathrm{~mm}$ holes.

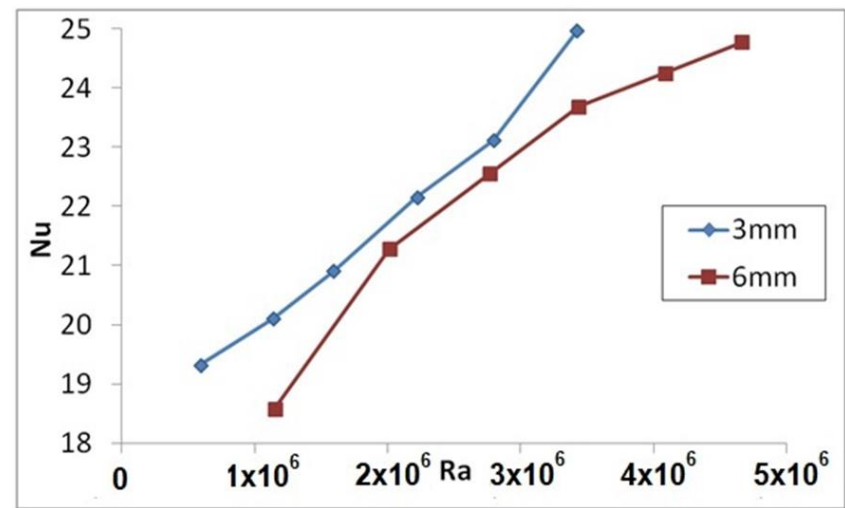

Figure 9. Calculated Nusselt numbers versus Rayleigh numbers for two different hole diameters 


\section{Conclusion}

Two identical heat sinks with sinusoidal wavy fins were perforated with two different hole diameters, namely $3 \mathrm{~mm}$ and $6 \mathrm{~mm}$. Heat sinks over an electrical heater were heated with six different heating powers. Heat sink temperatures were recorded for transient and steady state operations. Nusselt and Rayleigh numbers were calculated at steady state conditions for comparing natural convection heat transfer of the two heat sinks. Following conclusions and remarks for future studies are drawn.

Conclusions:

- An increase of $5 \mathrm{~W}$ in electrical heater changes the heat sink temperature about $10 \mathrm{~K}$.

- Steady state temperature values of the heat sinks are increasing linearly with the heating power. More heating power with the same natural convection heat transfer surface area means that convection coefficient increases since the trend of surface temperature increase is linear. Otherwise, the trend would get a parabolic shape. Nusselt number in Figure 9 justifies this finding.

- Although the wall temperatures suggest that $6 \mathrm{~mm}$ hole diameter heat sink yielded better heat transfer, the difference between temperature trends is due to difference between ambient air temperatures during experiments. This is justified by Figure 9. The slope of temperature trends is important, indicating the cooling performance of the heat sinks in terms of industrial application. And trends are almost same, indicating that there is no significant difference. However, dimensionless comparison is the ultimate and correct comparison tool.

- $3 \mathrm{~mm}$ holes performed significantly better in terms of Nusselt number.

- There should be an optimum between non perforated fins and $6 \mathrm{~mm}$ perforation. The optimum should be around $3 \mathrm{~mm}$ diameter since it gives better results comparing to $6 \mathrm{~mm}$ holes.
Remarks for future work:

- Heating power should be controlled by means of an electronic control system such as proportionalintegral-derivative controller (PID) in order to provide more stable heat transfer rate and constant heating power.

- Transient heating power should be recorded depending on time for the dimensionless parameter calculations.

- Thermal camera can be used not only for measuring temperature distribution on fins but also distinguishing the thermal radiation.

- In the absence of thermal camera, fin temperature distribution can be measured with several thermocouples. Fin efficiencies can be calculated accordingly.

- A vacuum chamber can be used in order to determine the radiation heat transfer rate for certain temperatures in order to distinguish convection heat transfer from total heat transfer.

- A correlation expression can be derived including hole diameters and heating power as variables alongside with the experimental and correlation uncertainties.

- Computational Fluid Dynamics can be used in order to highlight the flow mechanics leading to heat transfer differences.

- Considering the flow patterns, different hole configurations and dimensions can be tested for optimization purposes considering a certain operational condition. Several operational conditions can also be investigated.

\section{Acknowledgment}

Data and theory of the present paper are prepared from the MSc. study of the first author; Mohammed Salam Taha Taha. Authors also acknowledge the experimental setup and infrastructure of School of Civil Aviation of Selcuk University; which is established for the MSc of Ziylan [11].

\section{Nomenclature}

\begin{tabular}{|ll|ll|}
\hline $\mathrm{A}$ & $:$ Plate surface area $\left(\mathrm{m}^{2}\right)$ & $\mathrm{Ra}$ & $:$ Rayleigh number \\
$\mathrm{h}$ & $:$ Heat transfer coefficient $\left(\mathrm{W} / \mathrm{m}^{2} \mathrm{~K}\right)$ & $\mathrm{T}_{\mathrm{f}}$ & $:$ Film temperature $(\mathrm{K})$ \\
$\mathrm{k}$ & $:$ Thermal conductivity $(\mathrm{W} / \mathrm{mK})$ & $\mathrm{T}_{\mathrm{W}}$ & $:$ Plate surface temperature $(\mathrm{K})$ \\
$\mathrm{H}$ & $:$ High of fins $(\mathrm{mm})$ & $\mathrm{T}_{\infty}$ & $:$ Ambient temperature $(\mathrm{K})$ \\
$\mathrm{n}$ & $:$ Number of fins & $\mathrm{V}$ & $:$ Voltage $(\mathrm{V})$ \\
$\mathrm{Nu}$ & $:$ Nusselt number & $\mathrm{W}$ & $:$ Width of fins $(\mathrm{mm})$ \\
$\mathrm{P}$ & $:$ Power $(\mathrm{W})$ & $\beta$ & $:$ Volumetric coefficient of \\
$\mathrm{Q}_{\text {loss }}$ & $:$ Heat transfer loss $(\mathrm{W})$ & & expansion $(1 / \mathrm{K})$ \\
$\mathrm{Q}_{\text {radiation }}$ & $:$ Heat transfer by radiation $(\mathrm{W})$ & $\Delta \mathrm{T}$ & $:$ Temperature difference $(\mathrm{K})$ \\
$\mathrm{Q}_{\text {convection }}$ & $:$ Heat transfer by convection & & \\
\hline
\end{tabular}




\section{References}

[1] Harahap F., McManus Jr.-H.N., 1967, "Natural convection heat transfer from horizontal rectangular fin arrays", J. Heat Transfer, 89(1), 32-38.

[2] Liang, C.Y., Yang, W.J., 1975, "Heat transfer and friction loss performance of perforated heat exchanger surfaces", Journal of Heat Transfer, 97(1), 9-15.

[3] Patankar, S.V., and Prakash., C., 1981, "An analysis of the effect of plate thickness on laminar flow and heat transfer in interrupted plate passage", International Journal of Heat and Mass Transfer, 24(11), 1801-1810.

[4] Mhamuad, A.M., Ibrahim, T.K., Jasim, R.R., 2008, "Determination of the temperature distribution the perforated fins under natural convection", Tikrit Journal of Engineering Sciences, 15(2), 63-78.

[5] Shaeri, M.R., Yaghoubi, M., Jafarpur, K., 2009, "Heat transfer analysis of lateral perforated fin heat sinks", Applied Energy, 86(10), 2019-2029.

[6] Masao, F., Yu, S., Goro, Y., 1988, "Heat transfer and pressure drop of perforated surface heat exchanger with passage enlargement and contraction" International Journal of Heat and Mass Transfer, 31(1), 135-142.

[7] Kumbhar, D.G., Sane, D.N., Chavan, S.T., 2009, "Finite element analysis and experimental study of convective heat transfer augmentation from horizontal rectangular fin by triangular perforations" In Proc. of the International conference on Advances in Mechanical Engineering, 376-380.

[8] Qiu, Y., Tian, M., Guo, Z., 2013, "Natural convection and radiation heat transfer of an externally-finned tube vertically placed in a chamber", Heat and Mass Transfer, 49(3), 405-412.

[9] AlEssa, A.H., Al-Odat, M.Q., 2009, "Enhancement of natural convection heat transfer from a fin by triangular perforations of bases parallel and toward its base", The Arbian Journal for Science and Engineering, 34(2).

[10] Kim, D. K., 2012, "Thermal optimization of plate-fin heat sinks with fins of variable thickness under natural convection", International Journal of Heat and Mass Transfer, 55(4), 752-761.

[11] Altun, A. H., \& Ziylan, O. (2019). Experimental investigation of the effects of horizontally oriented vertical sinusoidal wavy fins on heat transfer performance in case of natural convection. International Journal of Heat and Mass Transfer, 139, 425-431. 


\section{CORRECTION LETTER}

04.05.2019

To Editorial Office of International Journal of Energy Applications and Technologies,

As corresponding author of "10.31593-ijeat.505116-619638" numbered "Natural convection from perforated vertical fins with different hole diameters" titled paper, I have to notice you about a major correction in the paper. Full reference of the paper is given below.

Mohammed Salam Taha Taha, Ali Ateş, Aziz Hakan Altun, Eyüb Canll, "Natural convection from perforated vertical fins with different hole diameters", International Journal of Energy Applications and Technologies 5(4) [2018] 174-180

We noticed during further work on the data which was also used for the above mentioned paper that heater power are calculated wrong during data reduction process. Voltage value in equation (8) was taken as grid value although we should had taken voltage value acting on electrical heater. The correct voltage values have been drawn from measurements and related calculations. Correct graphics and accordingly new evaluations and comments are inserted to the corrected version of the manuscript. A comparison table is given as an attachment to this letter for major corrections. We are also granting permission to publication of this letter if necessary.

Sincerely,

\section{Eyub CANLI}

Corresponding Author

ecanli@selcuk.edu.tr

Appendix: Comparison Table of Corrections 
Appendix: Comparison Table of Corrections

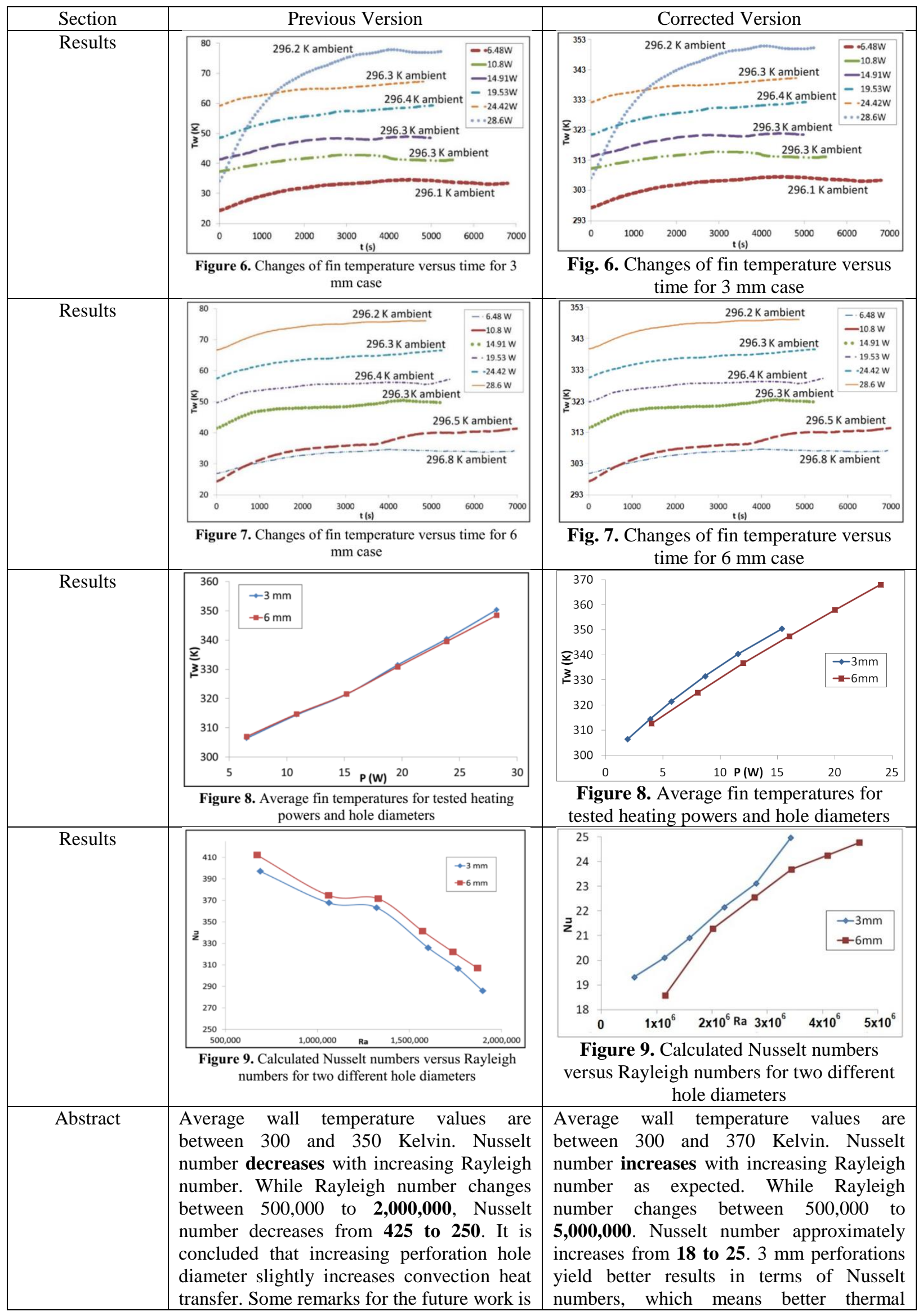




\begin{tabular}{|c|c|c|}
\hline & given in conclusion section. & $\begin{array}{l}\text { convection. Surface temperature trends are } \\
\text { similar according to power increments. } \\
\text { Considering experimental uncertainty, } \\
\text { general performances of the two heat sinks } \\
\text { are found similar. Some remarks for the } \\
\text { future work are given in conclusion section. }\end{array}$ \\
\hline Introduction & $\begin{array}{l}\text { This work distinguishes from the literature } \\
\text { by its specific sinusoidal wavy fins with a } \\
\text { certain amplitude on a base plate as a heat } \\
\text { sink for natural convection heat transfer. }\end{array}$ & $\begin{array}{l}\text { This work distinguishes from the literature } \\
\text { by its specific sinusoidal wavy fins with a } \\
\text { certain amplitude on a base plate as a heat } \\
\text { sink for natural convection heat transfer. Fin } \\
\text { amplitude is arranged as fin height divided } \\
\text { by } 30(\mathrm{H} / 30) \text {. }\end{array}$ \\
\hline $\begin{array}{l}\text { Material and } \\
\text { Methods }\end{array}$ & $\begin{array}{l}\text { Yet, it is also verified by calculating the } \\
\text { power using the ampere value of the circuit } \\
\text { using a digital multimeter (VOM) and } \\
\text { multiplying it with the known grid voltage } \\
\text { which is } 220 \mathrm{~V} \text {. }\end{array}$ & $\begin{array}{l}\text { Yet, it is also verified by calculating the } \\
\text { power using the values of electrical current } \\
\text { and voltage measured by a digital } \\
\text { multimeter (VOM). }\end{array}$ \\
\hline $\begin{array}{l}\text { Material and } \\
\text { Methods }\end{array}$ & $\begin{array}{l}\text { Because, it was desired to have the steady } \\
\text { state operation conditions. }\end{array}$ & $\begin{array}{l}\text { Because, steady state operation conditions } \\
\text { were desired to be achieved for calculations. }\end{array}$ \\
\hline Results & $\begin{array}{l}\text { There are six power values for the } \\
\text { experiments and the first three do not show a } \\
\text { significant difference between } 3 \text { mm } \\
\text { perforations and } 6 \mathrm{~mm} \text { perforations. For the } \\
\text { remaining three power values, which change } \\
\text { from } 20 \mathrm{~W} \text { to } 30 \mathrm{~W} \text {, hole diameters } \\
\text { distinguish from each other and } 3 \mathrm{~mm} \text { hole } \\
\text { diameter exhibits higher final temperatures } \\
\text { implying that } 6 \mathrm{~mm} \text { hole diameter resulted } \\
\text { better convection. This inferring comes from } \\
\text { the fact that the trends in Figure } 8 \text { are for the } \\
\text { same heating powers yet } 6 \text { mm hole } \\
\text { diameters achieved the same heat transfer } \\
\text { rate with lesser temperature difference } \\
\text { values. However, considering the } \\
\text { experimental uncertainties and ambient air } \\
\text { temperatures, this difference cannot be used } \\
\text { to compare the convection of heat sinks. } \\
\text { Therefore dimensionless comparison should } \\
\text { be used. Figure } 9 \text { is given for Nusselt } \\
\text { numbers calculated for measured } \\
\text { temperatures of the heat sinks. Of course, } \\
\text { ambient temperature values are also used in } \\
\text { calculation of Nusselt numbers. Thus, Figure } \\
9 \text { is the final comparison for evaluating heat } \\
\text { sinks comparatively. }\end{array}$ & $\begin{array}{l}\text { Six heating power values are seen for each } \\
\text { heat sink when Figure } 8 \text { is examined. } \\
\text { Although absolute power values are not } \\
\text { coinciding, the important outcome is the } \\
\text { slope of the trend. Because, a lower slope } \\
\text { means less surface temperature increase } \\
\text { with power increments. Examination of the } \\
\text { slopes exhibits a similar behavior in terms of } \\
\text { surface temperature. Therefore, for } \\
\text { industrial applications, investigated heat } \\
\text { sinks do not differ from each other } \\
\text { significantly. Higher temperatures for } 3 \text { mm } \\
\text { heat sink are due to differences of ambient } \\
\text { air temperature. In order to justify this } \\
\text { statement and make a clear comparison in } \\
\text { terms of heat transfer, dimensionless } \\
\text { comparison is needed. Hence, Figure } 9 \text { is } \\
\text { provided showing Nusselt numbers of the } \\
\text { heat sinks versus Rayleigh number. Of } \\
\text { course, ambient temperature values are also } \\
\text { used in calculation of Nusselt numbers. } \\
\text { Thus, Figure } 9 \text { is the final comparison for } \\
\text { evaluating heat sinks comparatively. }\end{array}$ \\
\hline Results & $\begin{array}{l}\text { Figure } 9 \text { obviously shows that } 6 \mathrm{~mm} \text { hole } \\
\text { diameters on the same fin pattern exhibits } \\
\text { better heat transfer. Since almost all } \\
\text { parameters for the heat sinks are same } \\
\text { except the hole diameters, it can be } \\
\text { concluded that } 6 \mathrm{~mm} \text { holes lead to better } \\
\text { flow mixing and convection. It should also } \\
\text { be mentioned that Nusselt number is drawn } \\
\text { depending to Rayleigh number. Because, } \\
\text { Rayleigh number is an indicator of natural } \\
\text { convection flow. It is interesting to see that } \\
\text { both heat sinks yield an almost constant } \\
\text { Nusselt number between } 1,000,000 \text { and } \\
1,400,000 \text { Rayleigh number. Actually, the } \\
\text { trends of two heat sinks are almost same or }\end{array}$ & $\begin{array}{l}\text { Figure } 9 \text { obviously shows that } 3 \mathrm{~mm} \text { hole } \\
\text { diameters on the same fin pattern exhibits } \\
\text { significantly better convection heat transfer. } \\
\text { Since almost all parameters for the heat } \\
\text { sinks are same except the hole diameters, it } \\
\text { can be concluded that } 3 \mathrm{~mm} \text { holes lead to } \\
\text { better flow mixing and convection in } \\
\text { combination with the form of the fins and } \\
\text { the flow pattern due to the form of the fins. } \\
\text { It should also be mentioned that Nusselt } \\
\text { number is drawn depending to Rayleigh } \\
\text { number. Because, Rayleigh number is an } \\
\text { indicator of natural convection flow. As } \\
\text { fluid surrounding the fins gets higher } \\
\text { temperatures due to thermal convection, }\end{array}$ \\
\hline
\end{tabular}




\begin{tabular}{|c|c|c|}
\hline & $\begin{array}{l}\text { parallel. Only magnitudes are higher for } 6 \\
\mathrm{~mm} \text { hole diameter. As a conclusion, } \\
\text { perforation of the heat sink fins and making } \\
\text { them bigger for natural convection seem } \\
\text { favorable in respect of heat transfer. }\end{array}$ & $\begin{array}{l}\text { fluid expands and its density becomes lower. } \\
\text { Due to Buoyancy forces, a fluid motion } \\
\text { occurs. Form of the fins, combining with the } \\
\text { existence of the perforations, alter this fluid } \\
\text { motion and lead to different thermal } \\
\text { convection rates. As } 3 \mathrm{~mm} \text { hole diameter } \\
\text { resulted better convection heat transfer, and } \\
\text { considering that heat transfer area is also } \\
\text { higher for } 3 \mathrm{~mm} \text { case, this result indicates } \\
\text { that there is an optimum between non } \\
\text { perforated fins and } 6 \mathrm{~mm} \text { perforation. The } \\
\text { optimum should be around } 3 \text { mm diameter } \\
\text { since it gives better results comparing to } 6 \\
\text { mm holes. }\end{array}$ \\
\hline Conclusion & $\begin{array}{l}\text { Temperature values of the heat sinks are } \\
\text { increasing linearly with the heating power } \\
\text { implying that natural convection is } \\
\text { negatively effected by the temperature } \\
\text { difference and therefore wall temperature } \\
\text { increases. Nusselt number in Figure } 9 \\
\text { justifies this finding. The reason is thought } \\
\text { to be the constant gap between fins, } \\
\text { constituting a flow resistance for higher heat } \\
\text { transfer rates as the Rayleigh number } \\
\text { increases. }\end{array}$ & $\begin{array}{l}\text { Temperature values of the heat sinks are } \\
\text { increasing linearly with the heating power. } \\
\text { More heating power with the same natural } \\
\text { convection heat transfer surface area means } \\
\text { convection coefficient increases since the } \\
\text { trend of surface temperature increase is } \\
\text { linear. Otherwise, the trend would get a } \\
\text { parabolic shape. Nusselt number in Figure } 9 \\
\text { justifies this finding. }\end{array}$ \\
\hline Conclusion & $\begin{array}{l}\text { Although the wall temperatures are nearly } \\
\text { same for two heat sinks, } 6 \mathrm{~mm} \text { hole diameter } \\
\text { heat sink yielded better heat transfer } \\
\text { considering the Nusselt numbers graphic. } \\
\text { This is due to the less heat transfer area due } \\
\text { to the } 6 \mathrm{~mm} \text { hole gaps for the same heat } \\
\text { transfer rate. }\end{array}$ & $\begin{array}{l}\text { Although the wall temperatures suggest that } \\
6 \text { mm hole diameter heat sink yielded better } \\
\text { heat transfer, the difference between } \\
\text { temperature trends is due to difference } \\
\text { between ambient air temperatures during } \\
\text { experiments. This is justified by Figure } 9 . \\
\text { The slope of temperature trends is } \\
\text { important, indicating the cooling } \\
\text { performance of the heat sinks in terms of } \\
\text { industrial application. And trends are almost } \\
\text { same, indicating that there is no significant } \\
\text { difference. However, dimensionless } \\
\text { comparison is the ultimate and correct } \\
\text { comparison tool. }\end{array}$ \\
\hline Conclusion & $\begin{array}{l}\text { Both heat sinks have almost same or parallel } \\
\text { trends for Nusselt numbers versus Rayleigh } \\
\text { numbers. }\end{array}$ & $\begin{array}{l}3 \mathrm{~mm} \text { holes performed significantly better in } \\
\text { terms of Nusselt number. }\end{array}$ \\
\hline Conclusion & 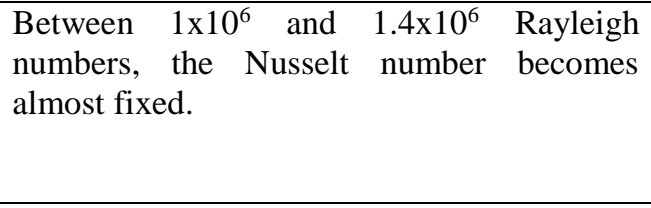 & $\begin{array}{l}\text { There should be an optimum between non } \\
\text { perforated fins and } 6 \mathrm{~mm} \text { perforation. The } \\
\text { optimum should be around } 3 \mathrm{~mm} \text { diameter } \\
\text { since it gives better results comparing to } 6 \\
\text { mm holes. }\end{array}$ \\
\hline Conclusion & $\begin{array}{l}\text { Perforation of the heat sink fins and making } \\
\text { them bigger for natural convection seem } \\
\text { favorable. }\end{array}$ & - \\
\hline
\end{tabular}

